\title{
Differences between the non-steroidal aromatase inhibitors anastrozole and letrozole - of clinical importance?
}

\author{
J Geisler*,I \\ IInstitute of Clinical Medicine, University of Oslo, Faculty Division at Akershus University Hospital, Sykehusveien 27, Lørenskog N-I 478, Norway
}

\begin{abstract}
Aromatase inhibition is the gold standard for treatment of early and advanced breast cancer in postmenopausal women suffering from an estrogen receptor-positive disease. The currently established group of anti-aromatase compounds comprises two reversible aromatase inhibitors (anastrozole and letrozole) and on the other hand, the irreversible aromatase inactivator exemestane. Although exemestane is the only widely used aromatase inactivator at this stage, physicians very often have to choose between either anastrozole or letrozole in general practice. These third-generation aromatase inhibitors (letrozole/Femara (Novartis Pharmaceuticals, Basel, Switzerland) and anastrozole/Arimidex (AstraZeneca, Pharmaceuticals, Macclesfield, Cheshire, UK)), have recently demonstrated superior efficacy compared with tamoxifen as initial therapy for early breast cancer improving disease-free survival. However, although anastrozole and letrozole belong to the same pharmacological class of agents (triazoles), an increasing body of evidence suggests that these aromatase inhibitors are not equipotent when given in the clinically established doses. Preclinical and clinical evidence indicates distinct pharmacological profiles. Thus, this review focuses on the differences between the non-steroidal aromatase inhibitors allowing physicians to choose between these compounds based on scientific evidence. Although we are waiting for the important results of a still ongoing head-to-head comparison in patients with early breast cancer at high risk for relapse (Femara Anastrozole Clinical Evaluation trial; 'FACE-trial'), clinicians have to make their choices today. On the basis of available evidence summarised here and until FACE-data become available, letrozole seems to be the best choice for the majority of breast cancer patients whenever a non-steroidal aromatase inhibitor has to be chosen in a clinical setting. The background for this recommendation is discussed in the following chapters.
\end{abstract}

British Journal of Cancer (201 I) 104, 1059-1066. doi:I0.1038/bjc.20 I I.58 www.bjcancer.com

Published online I March 201।

(C) 20II Cancer Research UK

Keywords: aromatase inhibitors; breast cancer; anastrozole; letrozole; exemestane

Adjuvant endocrine therapy has an important role in postmenopausal women (PMW) with hormone receptor-positive $(\mathrm{HR}+)$ breast cancer. Efficacy of anti-hormonal treatment of early breast cancer is based on the fact that estrogens may stimulate the growth of residual cancer cells or contribute to the initiation of a new primary cancer over time.

Selective estrogen-receptor (ER) modulators, such as tamoxifen, have been the gold standard of care for women with HR + breast cancer for the last 30 years (Jordan, 2004; Geisler et al, 2008). Tamoxifen therapy for 5 years can reduce the odds of recurrence and death by 47 and 26\%, respectively (Early Breast Cancer Trialists' Collaborative Group, 2005; Howell et al/ATAC Trialists Group, 2005).

Aromatase inhibitors (AIs) have now replaced tamoxifen as the standard of care for adjuvant endocrine therapy in the treatment of PMW with hormone-sensitive breast cancer. Three generations of AIs have been developed during the last 3 decades. Of these, the third-generation AIs have more favorable tolerability profiles and are more selective and/or potent compared with first- and secondgeneration agents (Nabholtz et al, 2000; Mouridsen et al, 2001).

* Correspondence: Professor J Geisler;

E-mail: juergen.geisler@medisin.uio.no

Received 16 August 2010; revised 4 January 201 I; accepted I4 January 201 I; published online I March $201 \mathrm{I}$
There are two broad categories of third-generation AIs (Lønning and Geisler, 2008). The reversible non-steroidal agents include anastrozole and letrozole (triazole derivatives). The third agent, exemestane, is an androstenedione derivative that functions as an irreversible steroidal inhibitor (or inactivator). The triazole derivatives bind to the cytochrome P-450 component of the aromatase enzyme, whereas the steroidal compound exemestane binds to the substrate-binding pocket of the aromatase enzyme (Geisler et al, 1998), leading to its degradation (Figure 1). AIs are now widely used as first-line therapy for PMW with hormonesensitive early breast cancer, as first-line therapy for metastatic disease, and as second-line agents in cases of tamoxifen resistance. This review emphasises the potency and emerging efficacy differences between third-generation AIs and places particular emphasis upon comparisons between anastrozole and letrozole.

\section{DIFFERENCES IN THE MECHANISM AND POTENCY OF AI-INDUCED ESTROGEN SUPPRESSION}

\section{In vitro results}

Several studies evaluating the reduction of aromatisation in vitro have compared the potency of third-generation AIs (Bhatnagar et al, 2001). Miller (1999) used two ex-vivo assays of aromatase activity in particular fractions of breast cancer tissue and in 
A<smiles>C=C1CC2C(CCC3(C)C(=O)CCC23)C2(C)C=CC(=O)C=C12</smiles>

B
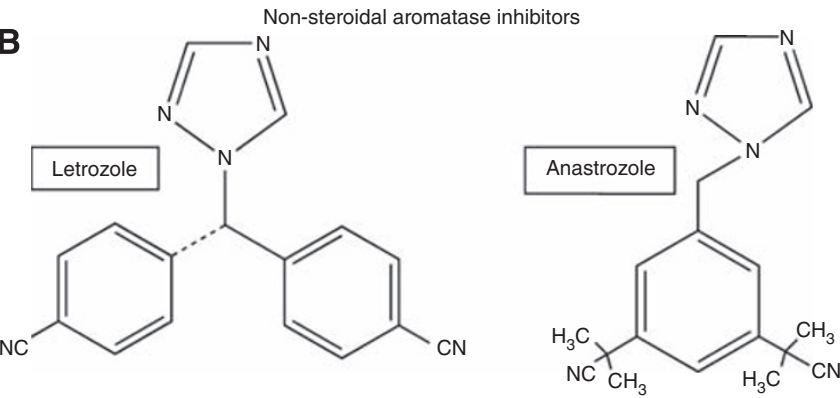

Figure I Chemical structures of currently used antiaromatase compounds (A) Steroidal aromatase inactivator. (B) Non-steroidal aromatase inhibitors.

mammary fibroblast cell cultures. Aromatase activity was effectively inhibited in both particular fractions of breast cancers and cultures of mammary adipose tissue fibroblasts. In another study by Miller et al (2001), immunohistochemical analyses revealed that treatment with anastrozole or letrozole resulted in significant decreases in progesterone receptor (PgR) expression, a marker for estrogen function. Bhatnagar et al (2001) demonstrated that in rodent cells, normal human adipose fibroblasts, and human cancer cell lines, letrozole was consistently 10-30 times more potent than anastrozole in its ability to inhibit intracellular aromatase. It is important to note, however, that in vitro assays may not accurately reflect the degree of inhibition produced/achieved in vivo.

\section{Animal models}

An intratumoural aromatase model system in mice was developed to mimic postmenopausal ER + breast cancer. This animal model takes into account the importance of locally produced (intratumoural) aromatase, as well as the fact that breast cancer occurs mainly in PMW. Although these mice (ovariectomised, athymic, and immunosuppressed nude mice) have no significant peripheral estrogen production capability and no adrenal androgen production, AI efficacy is assessed after inoculation with human breast carcinoma cells transfected with the human aromatase gene (MCF-7 arom cells) (Brodie et al, 2005). Using this aromatase xenograft model, letrozole was shown to be more effective than tamoxifen in suppressing breast tumour growth without causing endometrial proliferation. Additionally, tumours continuing to progress on tamoxifen therapy remained sensitive to second-line therapy with letrozole.

\section{In vivo measurements}

The biochemical efficacy of AIs in vivo may be determined from their effects on total body aromatisation, as well as from changes in plasma and tissue estrogen levels. Because of their high sensitivity, tracer methods that allow the calculation of whole-body aromatase inhibition are preferred (Lønning and Geisler, 2008). Unfortunately, these methods are labor-intensive, and analyses are usually limited to small numbers of patients. Plasma estrogen measurement is a cruder but simpler method that allows screening of much larger numbers of patients. As there may be significant variation
Table I Inhibition of whole-body aromatisation among three generations of aromatase inhibitors

\begin{tabular}{|c|c|c|c|c|}
\hline Generation & Compound & Dose (mg) & $\%$ Inhibition & Reference \\
\hline \multirow[t]{2}{*}{ First } & Aminoglutethimide & 250 qid & 90.6 & MacNeill et al (1992) \\
\hline & Formestane (IM) & $2502 w$ & 84.8 & Jones et al (1992) \\
\hline \multirow[t]{5}{*}{ Second } & & $5002 w$ & 91.9 & \\
\hline & & $500 w$ & 92.5 & \\
\hline & Formestane (po) & 125 od & 72.3 & MacNeill et al (1992) \\
\hline & & 125 bid & 70.0 & \\
\hline & & 250 od & 57.3 & \\
\hline \multirow[t]{3}{*}{ Second } & Rogletimide & 200 bid & 50.6 & MacNeill et al (1992) \\
\hline & & 400 bid & 63.5 & \\
\hline & & 800 bid & 73.8 & \\
\hline \multirow[t]{2}{*}{ Second } & Fadrozole & I bid & 82.4 & Lønning et al (199|) \\
\hline & & 2 bid & 92.6 & \\
\hline \multirow[t]{2}{*}{ Third } & Anastrozole & I od & 96.7 & Geisler et al (1996) \\
\hline & & I od & 97.3 & Geisler et al (2002) \\
\hline \multirow[t]{2}{*}{ Third } & Letrozole & $2.5 \mathrm{od}$ & $>98.9$ & Dowsett et al (1995) \\
\hline & & $2.5 \mathrm{od}$ & $>99.1$ & Geisler et al (2002) \\
\hline Third & Exemestane & 25 od & 97.9 & Geisler et al (1998) \\
\hline
\end{tabular}

Abbreviations: od = once daily; bid = twice daily; qid = four times daily; $w=$ weekly; $2 \mathrm{w}=$ twice weekly; $\mathrm{po}=$ oral; $\mathbb{I M}=$ intramuscular. ${ }^{\mathrm{a}}$ Detected in a direct, intrapatient crossover study.

between local estrogen synthesis in addition to uptake of estrogens from the circulation in some tumours, direct measurement of intratumour estrogens is required to assess the potency of AI estrogen suppression in malignant target tissues (Lønning and Geisler, 2008).

The third-generation AIs approved by the Food and Drug Administration (anastrozole, letrozole, and exemestane) are highly selective competitive inhibitors/inactivators of the aromatase enzyme. Although first- and second-generation AIs inhibit estrogen synthesis in vivo up to $90 \%$, third-generation compounds reproducibly cause $\geqslant 98 \%$ aromatase inhibition in humans (Geisler et al, 2008). Table 1 provides a comparison of the total body aromatase inhibition of third-generation AIs compared with the first- and second-generation compounds. Furthermore, suppression of plasma levels of estrogens by $>90 \%$ has been consistently demonstrated with all third-generation AIs (Dowsett et al, 1995; Geisler et al, 1996, 1998, 2002, 2008).

Among third-generation AIs, letrozole seems to produce the most extensive estrogen suppression. Results from an intrapatient crossover study revealed that letrozole $(2.5 \mathrm{mg}$ daily) consistently resulted in more potent aromatase inhibition compared with $1.0 \mathrm{mg}$ anastrozole (Geisler et al, 2002). In PMW undergoing primary treatment for locally advanced $\mathrm{ER}+/ \mathrm{PgR}+$ breast cancer, letrozole suppressed pretreatment tumour levels of estradiol (E2), estrone (E1), and estrone sulfate (E1S) by 97.6, 90.7, and 90.1\%, respectively (Figure 2A) (Geisler et al, 2008). This level of suppression is superior to that previously reported for anastrozole using the same methods: 89.0, 83.4, and $72.9 \%$, respectively (Geisler et al, 2001). Direct comparisons of reanalyzed samples also found superior suppression of plasma estrogen levels with letrozole compared with anastrozole (Geisler et al, 2008), E2 (average suppression by 95.2 vs $92.8 \% ; P=0.018)$, E1 $(98.8 \%$ suppression vs $96.3 \% ; P=0.003)$, and E1S (98.9\% suppression $v s$ 95.3\%; $P=0.003$ ) (Figure 2B). Recently, Dixon et al (2008) confirmed that letrozole reduces plasma estrogen levels to a greater degree than does anastrozole at clinical doses. The results of these two translational studies, Geisler et al (2008) and Dixon et al (2008), raise the question of whether differences in potency translate into differences of clinical importance. Although it has been postulated by some authors that aromatase inhibition above a defined level (f. eks. 90\% inhibition) might not increase the clinical efficacy, the lessons we learned from clinical studies through the last 3 decades suggest that estrogen suppression and clinical efficacy are tightly correlated also above $90 \%$ aromatase inhibition 

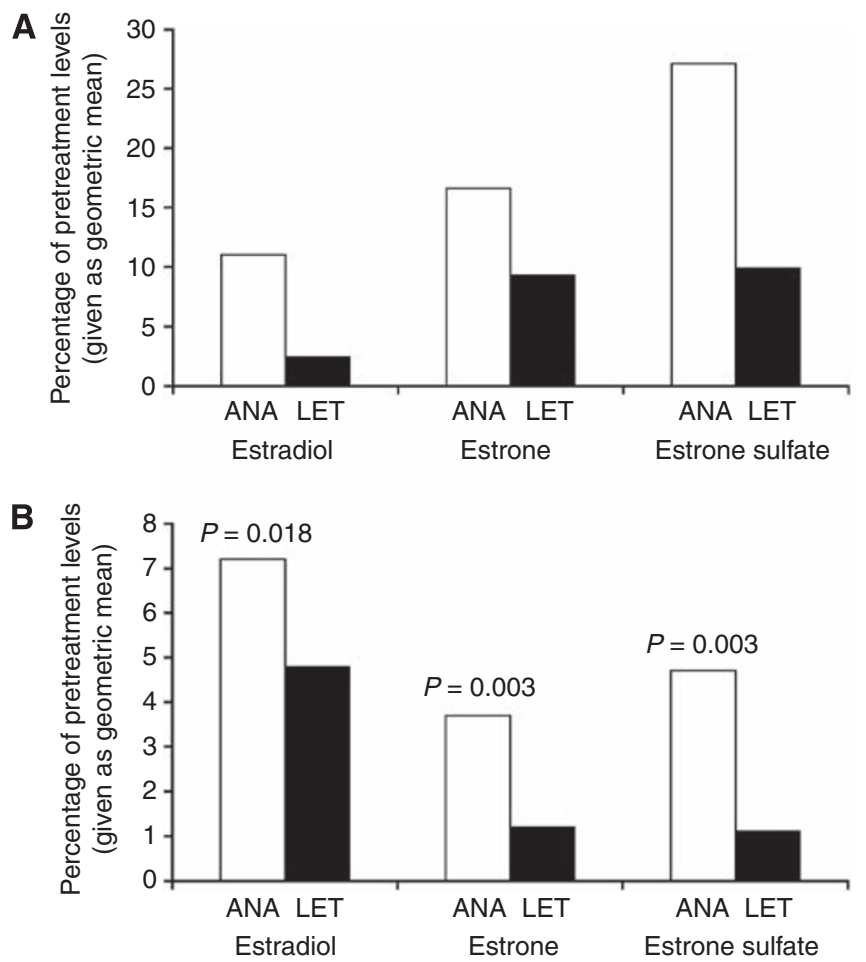

Figure 2 (A and $\mathbf{B}$ ) Influence of anastrozole (ANA) vs letrozole (LET) on tissue $(\mathbf{A})$ and plasma $(\mathbf{B})$ estrogen levels: percentage of pretreatment levels (given as geometric mean) (Geisler et al, 200I, 2008).

in vivo. One example is the head-to-head comparison of aminoglutethimide (aromatase inhibition: 90\%) and letrozole (aromatase inhibition: $>99 \%$ ) showing clearly superiority of letrozole in the setting of advanced breast cancer (Gershanovich et al, 1998). However, because of the very different side-effect profiles of aminoglutethimide and letrozole when given in the clinically established doses, with the latter being much less toxic, an influence of compliance problems during aminoglutethimide treatment on the study results cannot be excluded.

It is still a matter of discussion whether differences between 95 and $99 \%$ inhibition of aromatisation in vivo translate into significant different clinical response rates and times. In addition, although all major phase III trials performed with anastrozole and letrozole used the same doses of the individual drugs ( $1 \mathrm{mg}$ anastrozole once daily (o.d.) and $2.5 \mathrm{mg}$ letrozole o.d.), it might be questioned that the optimal clinical dose has been used at least for anastrozole. Although a direct intrapatient crossover trial with anastrozole $1 \mathrm{mg}$ o.d. $v s 10 \mathrm{mg}$ o.d. did not reveal a significant difference between the two daily doses, it is important to mention that 8 out of 10 patients experienced a better aromatase inhibition while on the $10 \mathrm{mg}$ o.d. dose (Geisler et al, 1996). In contrast, the corresponding study comparing letrozole $0.5 \mathrm{mg}$ o.d with $2.5 \mathrm{mg}$ o.d. did not reveal a major difference between the two tested doses (Dowsett et al, 1995). In conclusion, a suboptimal dosage of anastrozole cannot be totally ruled out. However, this problem cannot be solved by simply increasing the daily dose of anastrozole. This would require to repeat all phase III trials with the higher dose of anastrozole to evaluate clinical responses and even more important that is, side effects. With patents expiring for all aromatase inhibitors in a short-time frame, this is probably not of any interest for the involved pharmaceutical company.

\section{Clinical studies}

Neoadjuvant setting. Letrozole is the only AI that has been demonstrated to possess significantly superior efficacy to tamoxifen in the neoadjuvant setting, and is the only AI to have received approval from several countries for use in this setting. In a randomised, double-blind study in PMW $(N=337)$ with ER+ and/or PgR + breast cancer comparing letrozole with tamoxifen (Eiermann et al, 2001), letrozole was superior to tamoxifen in overall objective response rate (55 vs 36\%; $P<0.001)$. Furthermore, breast-conserving surgery (BCS) was possible in more patients treated with letrozole ( 45 vs $35 \% ; P=0.022)$. In another doubleblind study of PMW with ER + and/or PgR + breast cancer ineligible for BCS, patients were randomly assigned to receive either 4 months of neoadjuvant letrozole or tamoxifen (Ellis et al, 2001). Letrozole had a significantly better response rate (60 vs $41 \%$; $P=0.004)$, and letrozole-treated patients had significantly more BCS (48 vs 36\%; $P=0.036$ ). Differences in response rates were most marked for patients with human epidermal growth factor receptor (HER) $1 / 2+$ tumours ( 88 vs $21 \%$; $P=0.0004$ ).

The Pre-operative 'Arimidex' Compared To Tamoxifen Trial was a randomised, multicenter study comparing anastrozole $(n=228)$ with tamoxifen $(n=223)$ as neoadjuvant treatment in PMW with $\mathrm{HR}+$, large, operable breast cancer (Cataliotti et al, 2006). Objective responses for anastrozole and tamoxifen occurred in 39.5 and $35.4 \%$ of patients, respectively (ultrasound), and 50.0 and $46.2 \%$ of patients, respectively (caliper). In the intent-to-treat (ITT) population, surgery became feasible after 3 months of hormonal therapy in 38.1 vs $29.9 \%$ of anastrozole- and tamoxifentreated patients, respectively $(P=0.11)$. In patients receiving endocrine therapy only $(n=314)$, surgery became feasible in $43 \%$ of patients receiving anastrozole $v s 30.8 \%$ receiving tamoxifen after 3 months of treatment $(P=0.04)$.

In contrast to these findings, the Immediate Preoperative Anastrozole, Tamoxifen, or Combined With Tamoxifen trial did not find any significant benefit with anastrozole compared with tamoxifen. Postmenopausal women with ER + invasive breast cancer were randomised to one of three treatment groups: neoadjuvant anastrozole $(n=113)$, tamoxifen $(n=108)$, or anastrozole plus tamoxifen $(n=109)$ (Smith et al, 2005). There were no significant differences in clinical objective response rates (caliper) across treatment groups ( $P=0.87$; anastrozole $v s$ tamoxifen).

The outcome of patients in need of neoadjuvant therapy may also be altered by the frequency of complete pathological responses during therapy with an AI. Although complete pathological responses have been observed in a study published by Dixon et al, these were not found in the corresponding group of patients treated with anastrozole (Dixon et al, 1999).

\section{Initial adjuvant setting}

\section{Early Breast Cancer}

Arimidex, Tamoxifen, Alone or in Combination (ATAC) trial: This phase III multinational, randomised, double-blind trial initially comprised 9366 PMW with breast cancer (Baum et al, 2002). It compared anastrozole alone or in combination with tamoxifen with tamoxifen monotherapy following breast cancer surgery. Combination therapy was not significantly more beneficial than tamoxifen alone, so the combination arm was terminated early, leaving further analyses limited to 6241 patients (Baum et al, 2002). At a median follow-up of 68 months, treatment with anastrozole in $\mathrm{HR}+$ patients revealed a significant benefit in disease-free survival (DFS) (hazard ratio (HR) $=0.83 ; 95 \%$ confidence interval (CI) $0.73-0.94 ; P=0.005)$ and time to recurrence (TTR) $(\mathrm{HR}=0.74 ; 95 \% \mathrm{CI}: 0.64-0.87 ; P=0.0002)$. However, there was no significant improvement in time to distant recurrence (TTDR; $\mathrm{HR}=0.84 ; 95 \% \mathrm{CI}$ : $0.70-1.00 ; P=0.06$ ) or overall survival (OS; $\mathrm{HR}=0.97$ ) in the relevant $\mathrm{HR}+$ patient population (Howell et al, 2005). At 100 months of follow-up, investigators observed a significant benefit in TTDR (risk of distant metastasis (DM)) in $\mathrm{HR}+$ patients receiving anastrozole $(\mathrm{HR}=0.84 ; 95 \%$ CI: $0.72-0.97, P=0.022)$. Anastrozole also 
Table 2 Key efficacy endpoints of major clinical trials across treatment settings

ATAC $^{\mathbf{a}}$

BIG I-98

\begin{tabular}{|c|c|c|c|c|c|c|}
\hline $\begin{array}{l}\text { Follow-up } \\
\text { (months) }\end{array}$ & 68 & 100 & 25.8 & 76 & 76 Censored $^{c}$ & 76 IPCW $^{c, d}$ \\
\hline DFS & $0.83(P=0.005)$ & $0.85(P=0.003)$ & $0.81(P=0.003)$ & $0.88(P=0.03)$ & 0.84 & 0.85 \\
\hline TTR & $0.74(P=0.0002)$ & $0.76(P=0.0001)$ & $0.72(P<0.001)$ & NR & NR & NR \\
\hline TTDR & $0.84(P=0.06)$ & $0.84(P=0.022)$ & $0.73(P=0.001)$ & $0.85(P=0.05)$ & 0.81 & NR \\
\hline OS & $0.97(P=0.7)$ & $0.97(P=0.7)$ & $0.86(P=0.16)$ & $0.87(P=0.08)$ & 0.81 & 0.83 \\
\hline Reference & Howell et al (2005) & Forbes et al (2008) & Thürlimann et al (2005) & Mouridsen et al (2009) & Mouridsen et al (2009) & Mouridsen et al (2009 \\
\hline
\end{tabular}

Abbreviations: ATAC = arimidex, tamoxifen, alone or in combination; BIG = breast international group; IPCW =inverse probability of censoring weighted analysis; NR = not reported; DFS = disease-free survival; TTR = time to recurrence; TTDR = time to distant recurrence; OS = overall survival ${ }^{a} \mathrm{Hormone}$ receptor-positive population. ${ }^{b}$ Intent-totreat population. 'Follow-up censored at selective crossover. ${ }^{\mathrm{d}}$ The weighting adjusts for factors associated with OS and with selective crossover, including baseline factors such as age, nodal status, tumour grade, and time varying performance status.

continued to provide a significant benefit in DFS $(\mathrm{HR}=0.85 ; 95 \%$ CI: $0.76-0.94 ; P=0.003$ ) and TTR (HR $=0.76$; 95\% CI: $0.67-0.87$; $P=0.0001)$. Although there were improvements in DFS, there was still no OS benefit for anastrozole vs tamoxifen (472 vs 477 events, respectively; $\mathrm{HR}=0.97 ; 95 \% \mathrm{CI}: 0.86-1.11 ; P=0.7$ ) (Forbes et al, 2008). The key efficacy endpoints of the ATAC trial across treatment settings are summarised in Table 2.

Breast International Group (BIG) 1-98 trial: This large international phase III, randomised, double-blind trial was independently run by the International Breast Cancer Study Group (IBCSG), a cooperative academic group interested in an analysis of letrozole vs tamoxifen in PMW with $\mathrm{HR}+$ breast cancer (ITT: $N=8010$; two-arm option: tamoxifen, $n=911$, letrozole, $n=917$; four-arm option: tamoxifen, $n=1548$, letrozole, $n=1546$, tamoxifen followed by letrozole, $n=1548$, letrozole followed by tamoxifen, $n=1540$ ) (Thürlimann et al, 2005). The key efficacy endpoints across treatment settings are summarised in Table 2.

Initial results $(N=8010)$ at a median follow-up of 25.8 months demonstrated the superiority of letrozole over tamoxifen in prolonging DFS and TTR (but not OS). Letrozole-treated patients had a significant early benefit in TTDR, with a $27 \%$ reduction in risk for DM at 25.8 months' median follow up (Thürlimann et al, $2005)$. A retrospective study $(N=7707)$ of BIG $1-98$ confirmed these results; there was a pronounced $30 \%$ reduction in early DM (at 2 years) with letrozole compared with tamoxifen (87 vs 125 events, respectively) (Mauriac et al, 2007). Based on the superiority of letrozole $v s$ tamoxifen at 25.8 months, the IBCSG decided to unblind the tamoxifen monotherapy arm only and to allow patients the choice to crossover to letrozole therapy; 619 (25.2\%) made the informed choice (with counseling) to crossover to the letrozole arm. As a result of the crossover, in addition to the ITT analysis, a censored analysis was performed to account for crossover patients (Mouridsen et al, 2009). Analysis of ITT patients at a median follow-up of 76 months of letrozole or tamoxifen monotherapy demonstrated a continued significant benefit in DFS (HR $=0.88$; 95\% CI: $0.78-0.99 ; P=0.03)$ and TTDR ( $\mathrm{HR}=0.85 ; 95 \% \mathrm{CI}: 0.72-1.00 ; P=0.05$ ) with letrozole (Mouridsen et al, 2009). There were 40 fewer deaths with letrozole, demonstrating an emerging survival benefit (303 vs 343; HR= $0.87 ; 95 \%$ CI: $0.75-1.02 ; P=0.08)$. In the censored analysis, accounting for patients who crossed-over to letrozole, letrozoletreated patients had benefit in DFS (HR $=0.84 ; 95 \%$ CI: $0.74-0.99)$, TTDR (HR $=0.81 ; 95 \%$ CI: $0.68-0.96)$, and OS (HR $=0.81 ; 95 \% \mathrm{CI}$ : $0.69-0.94)$. However, the IBCSG concluded that early crossover to letrozole possibly biased the ITT analysis in favour of tamoxifen and the censored analysis in favour of letrozole, making accurate assessments of OS difficult. To adjust for this potential bias, an additional inverse probability of censoring weighted analysis was carried out to provide a more accurate estimate of the clinical benefit of letrozole. The results demonstrated that 5 years of letrozole significantly improved DFS by $15 \%(\mathrm{HR}=0.85 ; 95 \%$ CI: $0.76-0.96)$ and OS by $17 \%(\mathrm{HR}=0.83$; 95\% CI: $0.7-0.97$; $P<0.05$ ) (Giobbie-Hurder et al, 2009), reflecting the statistics that might have been observed in the absence of selective crossover (Mouridsen et al, 2009). It is important to note that with the emergence of significantly improved treatments, the issue of crossover is being addressed in many trials and is not unique to this trial.

\section{IMPLICATIONS OF CYP2D6 GENOTYPE}

The potential effect of CYP2D6 genetic variants on clinical response in tamoxifen-treated breast cancer patients has recently gained much interest. CYP2D6 is predominantly responsible for the 4-hydroxylation of tamoxifen leading to its most active metabolites, 4-hydroxytamoxifen and endoxifen (Dehal and Kupfer, 1997). CYP2D6 poor metabolisers have been reported to be at higher risk for recurrence compared with CYP2D6 wild-type patients (Schroth et al, 2009). Although the data are still somewhat conflicting at this point (Dezentjé et al, 2009), CYP2D6 genotyping might become the first predictive factor in breast cancer patients that may be analysed in a blood sample in the near future. The reported differences between the tamoxifen arms and the AI-arms in the large clinical phase III studies in early breast cancer have to be re-evaluated in the light of these novel findings.

\section{INFLUENCE ON DISTANT METASTASIS}

Indirect information from the ATAC and BIG 1-98 trials indicates that differences in clinical efficacy exist between anastrozole and letrozole in the initial adjuvant setting. Both AIs improve DFS compared with tamoxifen in patients with $\mathrm{HR}+$ disease. The most common type of recurrence seen 2 to 3 years post surgery is DM, a well-recognised predictor of breast cancer survival (Saphner et al, 1996; Mansell et al, 2009). Only letrozole has been shown to significantly reduce early DM events (30\% reduction in the risk of $\mathrm{DM}$ at 2 years) (Mauriac et al, 2007). A significant reduction in DM events was also seen with anastrozole in $\mathrm{HR}+$ patients but only at 100 months of follow-up (Forbes et al, 2008). In contrast, exploratory analysis of the ATAC trial confirmed that most of the early benefit with anastrozole was not in the prevention of distant disease; at 2.5 years, there was a $7 \%$ benefit in the prevention of DM (Houghton, 2006).

\section{NOVEL ANTIESTROGENS VS AROMATASE INHIBITORS}

The development of fulvestrant (Faslodex, AstraZeneca, Pharmaceuticals, Macclesfield, Cheshire, UK), a unique ER 
Table 3 Incidence (\%) of third-generation aromatase inhibitor-related adverse events compared with tamoxifen

\begin{tabular}{|c|c|c|}
\hline & Anastrozole & Letrozole \\
\hline Study & ATAC & $\mathrm{BIG} \mid-98$ \\
\hline N & 6186 & 8010 \\
\hline Follow-up (mos) & 68 & 60.5 \\
\hline Arthralgia & $\begin{array}{c}35.6 \text { vs } 29.4 \\
P<0.0001\end{array}$ & $\begin{array}{c}21.9 \text { vs } 16.5 \\
N R\end{array}$ \\
\hline Osteoporosis & $N R$ & $N R$ \\
\hline Fractures & $\begin{array}{l}|| 1.0 \text { vs } 7.7 \\
P<0.000 \mid\end{array}$ & $\begin{array}{c}7.5 \text { vs } 5.7 \\
\text { NR }\end{array}$ \\
\hline Hot flashes & $\begin{array}{c}35.7 \text { vs } 40.9 \\
P<0.0001\end{array}$ & $\begin{array}{c}35.2 \text { vs } 39.5 \\
\text { NR }\end{array}$ \\
\hline Hypercholesterolemia & NR & $\begin{array}{c}48.7 \text { vs } 24.1 \\
\text { NR }\end{array}$ \\
\hline Overall cardiac events & $N R$ & $\begin{array}{c}5.6 \text { vs } 5.4 \\
\text { NR }\end{array}$ \\
\hline Ischemic cardiovascular disease & $\begin{array}{c}4.1 \text { vs } 3.4 \\
P=0.1\end{array}$ & $\begin{array}{c}2.1 \text { vs } 1.7 \\
N R\end{array}$ \\
\hline Reference & Howell et al (2005) & Thürlimann et al (2009) \\
\hline
\end{tabular}

Abbreviations: $\mathrm{ATAC}=$ arimidex, tamoxifen, alone or in combination; $\mathrm{BIG}=$ breast international group; NR= not reported; NS = not significant.

antagonist and downregulator has caused considerable attention. Although experience with fulvestrant in early breast cancer is limited at this point, recent head-to-head comparisons in the metastatic setting have revealed that fulvestrant $(500 \mathrm{mg}$ intramuscular (i.m.)/4 w) is at least as effective as anastrozole ( $1 \mathrm{mg}$ oral (p.o.)/o.d.) with significantly improved time to progression for patients in the fulvestrant arm (Robertson et al, 2009). Thus, the novel increased dosage of fulvestrant is a promising endocrine treatment option in all settings of breast cancer, and data for patients with early breast cancer are awaited in a short-time frame.

\section{THE FEMARA ANASTROZOLE CLINICAL EVALUATION TRIAL (FACE)}

Although the ATAC and BIG 1-98 trials have provided an extensive data set for anastrozole and letrozole in early breast cancer, no head-to-head trial of these two AIs has been conducted in this setting. The ongoing FACE trial was designed to prospectively address potential efficacy and safety differences (O'Shaughnessy, 2007). This phase III open-label, randomised, multicenter study includes node-positive patients randomised to receive either early adjuvant letrozole or anastrozole. The primary objective is to compare DFS at 5 years. Secondary objectives are to assess safety, OS, time to DM, and time to contralateral breast cancer. The trial was designed to differentiate between the two drugs in the shortest possible time by enrolling patients at increased risk of early recurrence of breast cancer, so that the number of events required to initiate analysis will be obtained more quickly. The results may help refine treatment strategies for PMW with breast cancer.

\section{ADVERSE EVENTS (AE) OF AI THERAPY}

Because of the extended duration of adjuvant endocrine therapy, patient tolerability issues and their potential influence on compliance and therapeutic outcome are important themes. All in all, third-generation AIs seem to have very similar toxicity profiles. Most side effects are explained by the general estrogen deprivation, predictable and similar to those of natural menopause. They may include hot flashes, arthralgia, osteoporosis, fractures, hypercholesterolemia, and cardiovascular events (see Table 3 for an overview). Side effects like thromboembolic events and endometrial cancer that are well established for antiestrogen therapy, are rarely seen during therapy with aromatase inhibitors. Although novel antiestrogens like raloxifene are less toxic compared with tamoxifen when tested head-to-head in women at increased risk for development of breast cancer, raloxifene has recently been shown to be less effective in preventing breast cancer, too (Vogel et al, 2010). Although adverse events of thirdgeneration AIs have been reviewed extensively in the available literature (Thürlimann et al, 2005; Buzdar et al, 2006; Coates et al, 2007; Coombes et al, 2007), this issue will only be briefly discussed here.

\section{Lipid metabolism and cardiovascular symptoms}

Blood cholesterol was comprehensively and systematically measured in the BIG 1-98 trial under non-fasting conditions every 6 months (Thürlimann et al, 2005). At a mean follow-up of 25.8 months, there was more hypercholesterolemia in the letrozole arm (43.6, vs $19.2 \%$ in the tamoxifen arm), but this $\mathrm{AE}$ was predominantly low grade. Importantly, median changes in cholesterol levels remained stable at 6,12 , and 24 months $(0,0$, and $-1.8 \%$ ) in the letrozole group but decreased in the tamoxifen group at each assessment $(-12.0,-13.5$, and $-14.1 \%)$. These results support a greater lipid-lowering effect of tamoxifen rather than a detrimental effect of letrozole. Safety analysis at a median of 60.5 months confirmed earlier results. Although there was an increased lipid impairment $v s$ tamoxifen, hypercholesterolemia was predominantly of low grade (Thürlimann et al, 2009).

In contrast, hypercholesterolemia was not a predefined $\mathrm{AE}$ in the ATAC trial; however, results indicated a significantly greater rate of hypercholesterolemia in the anastrozole arm than in the tamoxifen arm (9 vs 3\%; odds ratio 2.73; $P<0.0001$ ) (Buzdar et al, 2006). In conclusion, blood lipids seem to be slightly and equally increased during therapy with all third-generation AIs (anastrozole, letrozole, and exemestane) when compared directly with tamoxifen, because of the lipid-lowering effects of tamoxifen and not because of a lipid-increasing effect of AIs.

\section{Musculoskeletal symptoms and bone loss}

Up to $30 \%$ of all women taking AIs report myalgia or arthralgia. In the adjuvant setting, the rate of muculoskeletal symptoms is significantly higher for all third-generation AIs compared with tamoxifen. These events generally emerge early in treatment, are low grade and improve with time.

In addition, AIs cause a significant increase in both bone resorption and formation. Osteoporosis and increased fracture rates occur in some patients when using AIs (Table 3). Although preclinical studies suggested that bone loss may be less during treatment with a steroidal AI (exemestane) compared with nonsteroidal AIs (anastrozole and letrozole), there is no evidence at all from clinical trials confirming these hypotheses. In contrast, a randomised trial of healthy volunteers demonstrated that all AIs have a similar effect on burn turnover (McCloskey et al, 2006). Because of the early screening for osteopenia and osteoporosis whenever AIs are implemented in patients with early breast cancer and liberal use of calcium, vitamin $\mathrm{D}$, and bisphosphonates, the issue of bone loss seems to be solved for the majority of patients.

\section{Endocrine resistance and future research}

Acquired, as well as de novo, resistance to aromatase inhibition remains a major concern in clinical practice. Future research will seek to improve our understanding of how to treat AI-resistant breast cancers and, perhaps more importantly, how to prevent the onset of AI-induced resistance. Studies in model systems have suggested that tumour cells gradually adapt to low estrogen levels during AI-treatment, eventually acquiring resistance. However, early microarray profiling data suggest extensive heterogeneity in 
the resistance mechanisms involved. When estrogen levels are profoundly suppressed, in vitro models of de novo resistance suggest that tumour cells may have the capability to develop estrogen hypersensitivity through changes in gene expression and regulation of growth factor signalling pathways (Santen et al, 2005). On the basis of these findings, aromatase inhibitors and anti-HER-2 agents (trastuzumab, lapatinib) have been tested in combination in clinical studies showing improved progression-free survival in the combination arms (Johnston et al, 2009; Kaufman et al, 2009). Interestingly, recent data suggest also a complex recruitment of nuclear receptor co-activators/-suppressors to the $\mathrm{ER}$ during $\mathrm{AI}$ treatment in vivo (Flågeng et al, 2009). Thus, ER-cofactors have become an area of intense research aiming to develop novel drugs that may interfere with the ER-cofactor complexes. Other determinants of endocrine resistance in breast cancer patients have recently been reviewed by Musgrove and Sutherland (2009).

The development of novel aromatase antibodies like antibody 677 may provide novel tools for the identification of PMW with $\mathrm{ER}+$ and aromatase-positive tumours that will respond to AI therapy before it is initiated (Geisler et al, 2010).

\section{CONCLUSIONS}

Aromatase inhibition is now established as standard care in both early and metastatic breast cancer for $\mathrm{HR}+\mathrm{PMW}$ following crucial phase III trials involving $>30000$ patients. Highest in-vivo potency, with superior E2 suppression in human breast cancer tissue, has been demonstrated with letrozole compared with anastrozole. In addition to being the most potent non-steroidal AI, letrozole is the only AI that has demonstrated superior efficacy in both the neoadjuvant and adjuvant settings compared with tamoxifen. A significant reduction of early DM in the adjuvant setting has been shown with letrozole, and a survival benefit is emerging with longer follow-up in the BIG 1-98 trial. In contrast, 100-month survival data from the ATAC trial do not demonstrate an OS benefit for anastrozole $v s$ tamoxifen. Third-generation AIs have a predictable and manageable safety profile, with AEs similar to symptoms of menopause. The severe AEs associated with tamoxifen are not observed with AIs. Direct head-to-head comparisons of AIs are needed to further elucidate differences among third-generation compounds. Until such data are available, the clinical data at hand suggest that the third-generation aromatase inhibitor letrozole may be the best choice when a non-steroidal AI is indicated.

Finally, whenever tamoxifen is used in clinical trials in the future, CYP2D6 genotyping should be implemented to further clarify the role of this potentially predictive marker.

\section{ACKNOWLEDGEMENTS}

Financial support for medical editorial assistance was provided by Novartis Pharmaceuticals. We thank Maria Soushko, PhD, of Phase Five Communications Inc. for medical editorial assistance with this manuscript.

\section{REFERENCES}

Baum M, Budzar AU, Cuzick J, Forbes J, Houghton JH, Klijn JG, Sahmoud T, ATAC Trialists' Group (2002) Anastrozole alone or in combination with tamoxifen $v s$ tamoxifen alone for adjuvant treatment of postmenopausal women with early breast cancer: first results of the ATAC randomized trial. Lancet 359: $2131-2139$

Bhatnagar AS, Brodie AMH, Long BJ, Evans DB, Miller WR (2001) Intracellular aromatase and its relevance to the pharmacological efficacy of aromatase inhibitors. J Steroid Biochem Mol Biol 76: 199-202

Brodie A, Jelovac D, Macedo L, Sabnis G, Tilghman S, Goloubeva O (2005) Therapeutic observations in MCF-7 aromatase xenografts. Clin Cancer Res 11: $884 \mathrm{~s}-888 \mathrm{~s}$

Buzdar A, Howell A, Cuzick J, Wale C, Distler W, Hoctin-Boes G, Houghton J, Locker GY, Nabholtz JM, (Arimidex, Tamoxifen, Alone or in Combination Trialists' Group) (2006) Comprehensive side effect profile of anastrozole and tamoxifen as adjuvant treatment for early-stage breast cancer: long-term safety analysis of the ATAC trial. Lancet Oncol 7: $633-643$

Cataliotti L, Buzdar AU, Noguchi S, Bines J, Takatsuka Y, Petrakova K, Dube P, de Oliveira CT (2006) Comparison of anastrozole vs tamoxifen as preoperative therapy in postmenopausal women with hormone receptor-positive breast cancer: the pre-operative 'Arimidex' compared to tamoxifen (PROACT) trial. Cancer 106: 2095-2103

Coates AS, Keshaviah A, Thürlimann B, Mouridsen H, Mauriac L, Forbes JF, Paridaens R, Castiglione-Gertsch M, Gelber RD, Colleoni M, Láng I, Del Mastro L, Smith I, Chirgwin J, Nogaret JM, Pienkowski T, Wardley A, Jakobsen EH, Price KN, Goldhirsch A (2007) Five years of letrozole compared with tamoxifen as initial adjuvant therapy for postmenopausal women with endocrine-responsive early breast cancer: update of study BIG 1-98. J Clin Oncol 25: 486-492

Coombes RC, Kilburn LS, Snowdon CF, Paridaens R, Coleman RE, Jones SE, Jassem J, Van de Velde CJ, Delozier T, Alvarez I, Del Mastro L, Ortmann O, Diedrich K, Coates AS, Bajetta E, Holmberg SB, Dodwell D, Mickiewicz E, Andersen J, Lønning PE, Cocconi G, Forbes J, Castiglione M, Stuart N, Stewart A, Fallowfield LJ, Bertelli G, Hall E, Bogle RG, Carpentieri M, Colajori E, Subar M, Ireland E, Bliss JM, Intergroup Exemestane Study (2007) Survival and safety of exemestane $v s$ tamoxifen after 2-3 years' tamoxifen treatment
(Intergroup Exemestane Study): a randomised controlled trial. Lancet 369: 559-570. Erratum in: Lancet 2007; 369: 906

Dehal SS, Kupfer D (1997) CYP2D6 Catalyzes Tamoxifen 4-Hydroxylation in Human Liver. Cancer Res 57: $3402-3406$

Dezentjé VO, Guchelaar H-J, Nortier JWR, van de Velde CJ, Gelderblom H (2009) Clinical implications of CYP2D6 Genotyping in Tamoxifen Treatment for Breast Cancer. Clin Cancer Res 15(1): 15-21

Dixon JM, Love CDB, Renshaw L, Bellamy C, Cameron DA, Miller WR, Leonhard RCF (1999) Lessons from the use of aromatase inhibitors in the neoadjuvant setting. Endoc Rel Cancer 6: 227-230

Dixon JM, Renshaw L, Young O, Murray J, Macaskill EJ, McHugh M, Folkerd E, Cameron DA, A'Hern RP, Dowsett M (2008) Letrozole suppresses plasma estradiol and estrone sulphate more completely than anastrozole in postmenopausal women with breast cancer. J Clin Oncol 26: $1671-1676$

Dowsett M, Jones A, Johnston SR, Jacobs S, Trunet P, Smith IE (1995) In vivo measurement of aromatase inhibition by letrozole (CGS 20267) in postmenopausal patients with breast cancer. Clin Cancer Res 1: $1511-1515$

Early Breast Cancer Trialists' Collaborative Group (EBCTCG) (2005) Effects of chemotherapy and hormonal therapy for early breast cancer on recurrence and 15-year survival: an overview of the randomized trials. Lancet 365: $1687-1717$

Eiermann W, Paepke S, Appfelstaedt J, Llombart-Cussac A, Eremin J, Vinholes J, Mauriac L, Ellis M, Lassus M, Chaudri-Ross HA, Dugan M, Borgs M, Letrozole Neo-Adjuvant Breast Cancer Study Group (2001) Preoperative treatment of postmenopausal breast cancer patients with letrozole: a randomized double-blind multicenter study. Ann Oncol 12: $1527-1532$

Ellis MJ, Coop A, Singh B, Mauriac L, Llombert-Cussac A, Jänicke F, Miller WR, Evans DB, Dugan M, Brady C, Quebe-Fehling E, Borgs M (2001) Letrozole is more effective neoadjuvant endocrine therapy than tamoxifen for ErbB-1- and/or ErbB-2-positive, estrogen receptor-positive primary breast cancer: evidence from a phase III randomized trial. J Clin Oncol 19: $3808-3816$

Flågeng MH, Moi LL, Dixon JM, Geisler J, Lien EA, Miller WR, Lønning PE, Mellgren G (2009) Nuclear receptor co-activators and HER-2/neu are 
upregulated in breast cancer patients during neo-adjuvant treatment with aromatase inhibitors. Br J Cancer 101: 1253-1260

Forbes JF, Cuzick J, Buzdar A, Howell A, Tobias JS, Baum M, Arimidex, Tamoxifen, Alone or in Combination (ATAC) Trialists' Group (2008) Effect of anastrozole and tamoxifen as adjuvant treatment for early-stage breast cancer: 100-month analysis of the ATAC trial. Lancet Oncol 9: 45-53

Geisler J, Detre S, Berntsen H, Ottestad L, Lindtjørn B, Dowsett M, Einstein Lønning P (2001) Influence of neoadjuvant anastrozole (Arimidex) on intratumoral estrogen levels and proliferation markers in patients with locally advanced breast cancer. Clin Cancer Res 7: 1230-1236

Geisler J, Haynes B, Anker G, Dowsett M, Lonning PE (2002) Influence of letrozole and anastrozole on total body aromatization and plasma estrogen levels in postmenopausal breast cancer patients evaluated in a randomized, cross-over study. J Clin Oncol 20: 751-757

Geisler J, Helle H, Ekse D, Duong NK, Evans DB, Nordbo Y, Aas T, Lonning PE (2008) Letrozole is superior to anastrozole in suppressing breast cancer tissue and plasma estrogen levels. Clin Cancer Res 14: $6330-6335$

Geisler J, King N, Anker G, Ornati G, Di Salle E, Lønning PE, Dowsett M (1998) In vivo inhibition of aromatization by exemestane, a novel irreversible aromatase inhibitor, in postmenopausal breast cancer patients. Clin Cancer Res 4: 2089-2093

Geisler J, King N, Dowsett M, Ottestad L, Lundgren S, Walton P, Kormeset PO, Lønning PE (1996) Influence of anastrozole (Arimidex), a selective, non-steroidal aromatase inhibitor, on in vivo aromatisation and plasma oestrogen levels in postmenopausal women with breast cancer. Br J Cancer 74: 1286-1291

Geisler J, Suzuki T, Helle H, Miki Y, Nagasaki S, Duong NK, Ekse D, Aas T, Evans DB, Lonning PE, Sasano H (2010) Breast cancer aromatase expression evaluated by the novel antibody 677: correlations to intratumor estrogen levels and hormone receptor status. J Steroid Biochem Mol Biol 118: 237-241

Gershanovich M, Chaudri HA, Campos D, Lurie H, Bonaventur A, Jeffrey M, Buzzi F, Bodrogi I, Ludwig H, Reichardt P, O'Higgins N, Romieu G, Friederich P, Lassus M (1998) Letrozole, a new oral aromatase inhibitor: randomised trial comparing $2.5 \mathrm{mg}$ daily, $0.5 \mathrm{mg}$ daily and aminoglutethimide in postmenopausal women with advanced breast cancer. Ann Oncol 9: 639-645

Giobbie-Hurder A, Price KN, Gelber RD, International Breast Cancer Study Group; BIG 1-98 Collaborative Group (2009) Design, conduct, and analyses of Breast International Group (BIG) 1-98: a randomized, double-blind, phase-III study comparing letrozole and tamoxifen as adjuvant endocrine therapy for postmenopausal women with receptorpositive, early breast cancer. Clin Trials 6: $272-287$

Houghton J (2006) Initial adjuvant therapy with anastrozole (A) reduces rates of early breast cancer recurrence and adverse events compared with tamoxifen (T) - data reported on behalf of the ATAC ('Arimidex', tamoxifen, alone or in Combination) Trialists' group. ESMO Meeting Abstract 243PD

Howell A, Cuzick J, Baum M, Buzdar A, Dowsett M, Forbes JF, Hoctin-Boes G, Houghton I, Locker GY, Tobias JS, ATAC Trialists' Group (2005) Results of the ATAC (Arimidex, Tamoxifen, Alone or in Combination) trial after completion of 5 years' adjuvant treatment for breast cancer. Lancet 365: $60-62$

Johnston S, Pippen Jr J, Pivot X, Lichinitser M, Sadeghi S, Dieras V, Gomez HL, Romieu G, Manikhas A, Kennedy MJ, Press MF, Maltzman J, Florance A, O'Rourke L, Oliva C, Stein S, Pegram M (2009) Lapatinib combined with letrozole $v s$ letrozole and placebo as first-line therapy for postmenopausal hormone receptor-positive metastatic breast cancer. J Clin Oncol 27: 5538-5546

Jones AL, MacNeill F, Jacobs S, Lonning PE, Dowsett M, Powles TJ (1992) The influence of intramuscular 4-hydroxyandrostenedione on peripheral aromatisation in breast cancer patients. Eur J Cancer 28A: 1712-1716

Jordan VC (2004) Selective estrogen receptor modulation: concept and consequences in cancer. Cancer Cell 5: 207-213

Kaufman B, Mackey JR, Clemens MR, Bapsy PP, Vaid A, Wardley A, Tjulandin S, Jahn M, Lehle M, Feyereislova A, Révil C, Jones A (2009) Trastuzumab plus anastrozole $v s$ anastrozole alone for the treatment of postmenopausal women with human epidermal growth factor receptor 2-positive, hormone receptor-positive metastatic breast cancer: results from the randomized phase III TAnDEM study. J Clin Oncol 27: $5529-5537$

Lønning PE, Geisler J (2008) Indications and limitations of third-generation aromatase inhibitors. Expert Opin Investig Drugs 17(5): 723-739
Lønning PE, Jacobs S, Jones A, Haynes B, Powles T, Dowsett M (1991) The influence of CGS 16949A on peripheral aromatisation in breast cancer patients. Br J Cancer 63: 789-793

MacNeill FA, Jones AL, Jacobs S, Lønning PE, Powles TJ, Dowsett M (1992) The influence of aminoglutethimide and its analogue rogletimide on peripheral aromatisation in breast cancer. Br J Cancer 66: 692-697

Mansell J, Monypenny IJ, Skene AI, Abram P, Carpenter R, Gattuso JM, Wilson CR, Angerson WJ, Doughty JC (2009) Patterns and predictors of early recurrence in postmenopausal women with estrogen receptorpositive early breast cancer. Breast Cancer Res Treat 117: 91-98

Mauriac L, Keshaviah A, Debled M, Mouridsen H, Forbes JF, Thürlimann B, Paridaens R, Monnier A, Lang I, Wardley A, Nogaret JM, Gelber RD, Castiglione-Gertsch M, Price KN, Coates AS, Smith I, Viale G, Rabaglio M, Zabaznyi N, Goldhirsch A, on behalf of BIG 1-98 Collaborative Group and International Breast Cancer Study Group (2007) Predictors of early relapse in postmenopausal women with hormone receptor-positive breast cancer in the BIG 1-98 trial. Ann Oncol 18: 859-867

McCloskey E, Hannon R, Lakner G, Clack G, Miyamoto A, Eastell R (2006) The letrozole (L), exemestane (E), and anastrozole (A) pharmacodynamics (LEAP) trial: A direct comparison of bone biochemical measurements between aromatase inhibitors (AIs) in healthy postmenopausal women. J Clin Oncol 24(18S): 16s (Abstract 555)

Miller WR (1999) Biology of aromatase inhibitors: pharmacology/ endocrinology within the breast. Endocr Relat Cancer 6: 187-195

Miller WR, Dixon JM, Cameron DA, Anderson TJ (2001) Biological and clinical effects of aromatase inhibitors in neoadjuvant therapy. J Steroid Biochem Mol Biol 79: 103-107

Mouridsen H, Gershanovich M, Sun Y, Pérez-Carrión R, Boni C, Monnier A, Apffelstaedt J, Smith R, Sleeboom HP, Jänicke $F$, Pluzanska A, Dank M, Becquart D, Bapsy PP, Salminen E, Snyder R, Lassus M, Verbeek JA, Staffler B, Chaudri-Ross HA, Dugan M (2001) Superior efficacy of letrozole $v s$ tamoxifen as first line therapy for postmenopausal women with advanced breast cancer: results of a phase III study of the International Letrozole Breast Cancer Group. J Clin Oncol 19: $2596-2606$

Mouridsen H, Giobbie-Hurder A, Goldhirsch A, Thürlimann B, Paridaens R, Smith I, Mauriac L, Forbes JF, Price KN, Regan MM, Gelber RD, Coates AS (2009) Letrozole therapy alone or in sequence with tamoxifen in women with breast cancer. $N$ Engl J Med 361: 766-776

Musgrove EA, Sutherland RL (2009) Biological determinants of endocrine resistance in breast cancer. Nat Rev Cancer 9: 631-643

Nabholtz JM, Buzdar A, Pollak M, Harwin W, Burton G, Mangalik A, Steinberg M, Webster A, von Euler M (2000) Anastrozole is superior to tamoxifen as first line therapy for advanced breast cancer in postmenopausal women: results of a North American multicenter randomized trial. Arimidex Study Group. J Clin Oncol 18: 3758-3767

O'Shaughnessy J (2007) A decade of letrozole: FACE. Breast Cancer Res Treat 105: $67-74$

Robertson FR, Llombart-Cussac A, Rolski J, Feltl D, Dewar J, MacPherson E, Lindemann J, Ellis MJ (2009) Activity of fulvestrant $500 \mathrm{mg} v s$ anastrozole $1 \mathrm{mg}$ as first-line treatment for advanced breast cancer: results from the FIRST study. J Clin Oncol 27(27): 4530-4535

Santen RJ, Song RX, Zhang Z, Kumar R, Jeng MH, Masamura A, Lawrence Jr J, Berstein L, Yue W (2005) Long-term estradiol deprivation in breast cancer cells up-regulates growth factor signaling and enhances estrogen sensitivity. Endocr Relat Cancer 12(Suppl 1): S61 -S73

Saphner T, Tormey DC, Gray R (1996) Annual hazard rates of recurrence for breast cancer after primary therapy. J Clin Oncol 14: 2738-2746

Schroth W, Goetz MP, Hamann U, Fasching PA, Schmidt M, Winter S, Fritz P, Simon W, Suman VJ, Ames MM, Safgran SL, Kuffel MJ, Ulmer HU, Boländer J, Strick R, Beckmann MW, Koelbl H, Weinshilboum RM, Ingle JN, Eichelbaum M, Schwab M, Brauch H (2009) Association between CYP2D6 polymorphisms and outcomes among women with early stage breast cancer treated with tamoxifen. JAMA 302(13): 1429-1436

Smith IE, Dowsett M, Ebbs SR, Dixon JM, Skene A, Blohmer JU, Ashley SE, Francis S, Boeddinghaus I, Walsh G, IMPACT Trialists Group. Neoadjuvant treatment of postmenopausal breast cancer with anastrozole, tamoxifen, or both in combination: the immediate preoperative anastrozole, tamoxifen, or combined with tamoxifen (IMPACT) multicenter double-blind randomized trial. J Clin Oncol 23: 5108-5116

Thürlimann B, for the BIG 1-98 Collaborative \& International Breast Cancer Study Groups (2009) Letrozole vs tamoxifen as adjuvant endocrine therapy for postmenopausal women with receptor-positive breast cancer update of the BIG 1-98 Primary Core Analysis (PCA). St Gallen Meeting Abstract (Abstract 0161) 
Thürlimann B, Keshaviah A, Coates AS, Mouridsen H, Mauriac L, Forbes JF, Paridaens R, Castiglione-Gertsch M, Gelber RD, Rabaglio M, Smith I, Wardley A, Price KN, Goldhirsch A, Breast International Group (BIG) 198 Collaborative Group (2005) A comparison of letrozole and tamoxifen in postmenopausal women with early breast cancer. $N$ Engl J Med 353: $2747-2757$

Vogel VG, Costantino JP, Wickerham DL, Cronin WM, Cecchini RS, Atkins JN, Bevers TB, Fehrenbacher L, Pajon ER, Wade JL, Robidoux A, Margolese RG, James J, Runowicz CD, Ganz PA, Reis SE, McCaskill-Stevens W, Ford LG, Jordan VC, Wolmark N (2010) Update of the National Surgical Adjuvant Breast and Bowel Project Study of Tamoxifen and Raloxifene (STAR) P-2 Trial: Preventing Breast Cancer. Cancer Prev Res 3(6): 696-706 